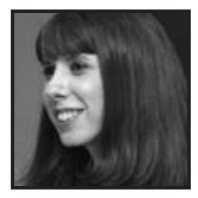

\title{
Poetic Bodies: Female Body Image, Sexual Identity and Arts-Based Research
}

\author{
Patricia Leavy, Stonehill College
}

\section{ABSTRACT}

This article reviews the use of a poetic form of analysis and representation of interview data collected on the topic of women's body image and sexual identity. The researcher developed a tri-voiced poetic method that merges participant, researcher and literature voices. In this article the author advocates tri-voiced poems as a way of sharing researcher viewpoints, opening up dialogue, challenging stereotypes, and reaching and educating broad audiences.

\author{
a prism of reflections \\ a mirrored world \\ fractured femininities \\ refracted back \\ that is what I see \\ when I look at the girls \\ surveying themselves \\ surveying me
}

(excerpted from "Girl Screens" by Patricia Leavy, 2009b)

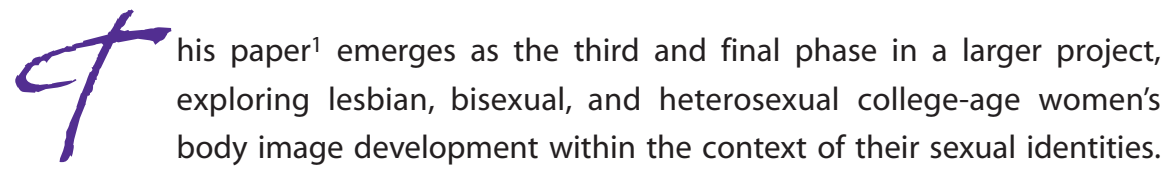


The initial interview project was represented in a traditional research article format (see Leavy \& Hastings, 2010). However, after completing the traditional write-up I felt the project was unfinished. I felt that while the traditional write-up may be useful for other scholars studying this topic, it had little potential to reach broader audiences, in every sense of the word "reach." For example, it was highly unlikely that college-age women would read the academic journal or that the writing would resonate with them. Therefore, there was little hope of using the research as a catalyst for education or dialogue. Further, I felt that I had not yet clearly communicated what I had learned based on this research as well as prior research in this area. I had learned a lot and developed a perspective that I wanted to share. Having written extensively about the importance of methodological innovation and emergent methods (see Hesse-Biber \& Leavy, 2006; 2008) and arts-based research practice (see Leavy, 2009), I decided to cycle back through the interview transcripts and literature review. After a second selfimmersion in the data I decided to turn to a poetry-based method of analysis, interpretation and representation. This too ended up taking two phases in order to figure out a way to accomplish my goals. I begin with a brief review of the original project and then I move into a discussion of poetic inquiry.

\section{The Project}

For the original study my research assistants and I conducted in-depth interviews (Berg, 2001; Weiss, 1994) with 28 college-age women in the northeast part of the United States in order to learn about their body image within the context of their sexual identities. We employed convenience sampling, soliciting local college students on their campuses and seeking participants via personal networks. Our sample consisted of 18 participants that identified as heterosexual and 10 participants that identified as lesbian or bisexual. An open-ended, unstructured interview approach was employed. After transcribing the in-depth interviews, two researchers coded the interview data for intercoder reliability. The result was a lengthy list of metacodes (large code categories) including such codes as: Attractiveness, Body Image, Family, Dating, and so forth. Under each metacode category there was a larger list of smaller, more specific code categories (also referred to as focused codes) such as: Attractiveness Ideals Others, Attractiveness Ideals Self, Body Satisfaction, Body Dissatisfaction, First Date, Date Preparation, etcetera. We then interpreted the data inductively from a feminist perspective. Our major findings suggested that women's internationalization or rejection of dominant femininity, the availability of viable (validated) alternative femininities, and one's place in subculture groups (as a mediator 
of dominant values) all converge to contribute to overall body image satisfaction and dissatisfaction. Moreover, through their largely unmitigated internalization of hegemonic femininity, the heterosexual participants experienced significantly more dissatisfaction than the lesbian and bisexual participants. ${ }^{2}$

After publishing the traditional research article I felt strongly that the "messages" and "feelings" of the women's stories had not been fully expressed in the traditional academic form. The "me too" moments women at times experience, did not come through in the academic prose. I also felt personally unfulfilled by the resulting academic writing. I doubted that the article would benefit other women. It was at this point that I decided to revisit the data and apply an arts-based approach to interpretation and representation.

\section{A Brief Review of Arts-Based Research Practice}

Arts-based research practices emerged from the 1970s to 1990s and now constitute a methodological genre within the expanded qualitative paradigm. Artsbased research developed out of a confluence of factors including: the social justice movements, the rise in autobiographical data, the rise in narrative inquiry, critical theoretical perspectives, and advances in embodiment theory (Leavy, 2009). Arts-based research has developed in an interdisciplinary methods context involving the crossing of disciplinary borders as well as cross-disciplinary collaborations. I define artsbased research practices as:

a set of methodological tools used by qualitative researchers across the disciplines during all phases of social research including data collection, analysis, interpretation, and representation. These emerging tools adapt the tenets of the creative arts in order to address social research questions in holistic and engaged ways in which theory and practice are intertwined. Arts-based methods draw on literary writing, music, performance, dance, visual art, film, and other mediums... Although a set of methodological tools, this genre of methods also comprises new theoretical and epistemological groundings that are expanding the qualitative paradigm. (Leavy, 2009, pp. 2-3)

For social researchers the appeal of the arts is in their ability to transform consciousness, refine the senses, promote autonomy, raise awareness, and express 
the complex feeling-based aspects of social life (Eisner, 2002, pp. 10-19). Arts-based research also draws on the oppositional, subversive, transformational, and otherwise resistive capabilities of the arts. It is not surprising that some critical scholars, feminists included, have an affinity for arts-based practices.

Free from academic jargon and other prohibitive barriers, the arts have the potential to be both emotionally and politically evocative for diverse audiences. The arts, at their best, can move people to see things in new ways or promote self-reflection. Moreover, the arts can promote dialogue which cultivates understanding or critical consciousness, can problematize dominant ideologies, and can unsettle stereotypes. In all of these respects, the arts can be used to educate.

\section{Poetic Analysis and Representation}

After considering various possibilities, I decided to use a poetic form of analysis and representation. I primarily turned to poems for their ability to emphasize, punctuate, merge multiple voices, and dislodge stereotypes. Poems open a space to represent data in ways that, for some researchers, are attentive to multiple meanings, identity work, and accessing subjugated perspectives. Differing from other forms of expression, in poems, the word, sound, and weighted space merge and it is this convergence that is critical to the construction and articulation of social meaning. In contrast to scientific assumptions that science clarifies while art obscures, Pelias (2004) suggests just the opposite:"Science is the act of looking at a tree and seeing lumber. Poetry is the act of looking at a tree and seeing a tree" (p. 9).

In this regard poems can cut through the clutter and jargon that weigh down academic writing. This dimension of poetry particularly appealed to me in this project because of my commitment to reaching broad audiences in an effort to open up a dialogue and develop critical consciousness as well as highlighting diverse women's "realities" in accessible ways. I was after a way to distill down the data and reach audiences of women for conversation and education. Kristeva (1984) posits that poetry can create a "traversal" by penetrating the symbolic order, creating a revolution in the linguistic and social spheres (p. 83). In this way poetry can be used for recognizing and rejecting patriarchal constructions; this was also a goal underpinning this project. 
There is a rich history of using poetic forms of analysis and representation for the reasons I have noted. While I will not attempt to replicate that history here, I offer a brief review. The idea of narrative poetry, or something similar to it, has also been labeled "research poetry" and "interpretive poetry" (Langer \& Furman, 2004), "investigative poetry" (Hartnett, 2003), and "ethnographic poetics" (Brady, 2004; Denzin, 1997). The term "poetic social science" used by Ellis and Bochner (2000) also speaks to these practices. Ethnographic poetics relies on taking ethnographic data (field notes, memo notes, and so forth), meditating on the data (as field researchers typically do), and presenting the results in the form of poems (Denzin, 1997). Similarly, Langer and Furman (2004) discuss interpretive poetry as a method of merging the participant's words with the researcher's perspective. This method of poetic representation therefore offers researchers a new way to account for merging the "voice" of their participants with their own insights, perhaps informed by a literature review and/or theoretical perspective. Alternatively, Langer and Furman (2004) present research poetry as a practice of creating poems from the research participant's words and speech style in order to produce a distilled narrative. Investigative poetry, as described by Hartnett (2003), combines critical ethnography, autobiography and political underpinnings in service of social justice oriented goals.

Sandra Faulkner (2005) suggests that a researcher considers using poetry when prose is insufficient in communicating what he or she wants to convey. This is exactly why I ended up turning to a poetic form of representation in this project. Further, Faulkner proposes using poetry as a means of provoking "emotional responses in readers and listeners in an effort to produce some shared experience" (p. 9). This too was a goal of mine insofar as I wanted to use the poetic works as a point of departure for a conversation with other women about the issues that emerged in the interviews (such as the pressures some women feel to conform to dominant and subculture norms of femininity). According to Miles Richardson (1998) poetry is also useful when we want to reveal a moment of truth. This form captures "moments" because "the intensity and compression of poetry emphasizes the vividness" of a moment (Ely et al., 1999, p. 135). Similarly, Laurel Richardson (1998) explains a part of humanity that may elude the social scientist, which reveals itself in poetry, allowing the audience to connect with something deep within them. The human connection, resonance and emotionality fostered by poetry results from the unique form poems occupy as compared with other styles of writing. Poems present a porthole onto an experience, one that may be shared by the reader or one that is new (Leavy, 2009). Again, these sentiments all underscored my turn to poetic representation. 


\section{Body Image and Sexuality: A Poetic Analysis}

Overall, the heterosexual research participants were significantly dissatisfied with numerous aspects of their bodies while the lesbian and bisexual participants were largely satisfied with their bodies. The heterosexual participants were particularly focused on "getting thin" and "getting a boy." The lesbian and bisexual participants noted important experiences linked to being both within and outside of dominant culture. In this vein many participants discussed traveling from subculture groups to dominant groups. I wanted to represent these issues poetically.

At first, I decided to employ a method of poetic transcription. "Poetic transcription" is an approach to analysis and writing that is derivative from a grounded theory perspective, where code categories develop inductively out of the data. The selected words and phrases become the basis of the poem. In addition to using participants' language, this approach is also meant to preserve narrators' speech patterns (Faulkner, 2005; Glesne, 1997). This technique relies on extensive thematic coding, constituting a process of reduction where single words may come to represent segments of an interview transcript. According to Madison (2005) this approach developed out of feminist and multi-culturalist concerns with respect to allowing the narrator's "voice" to emerge, concerns that are central to the larger project of feminism. Researchers committed to accessing subjugated voices might be especially inclined towards this interpretation style. Furthermore, as many critical scholars believe, the participant's narrative occurs at the point of articulation and therefore capturing the speech style of the narrator not only preserves his or her "voice" but also assists in communicating the performative aspects of the interview (Calafell, 2004; Faulkner, 2005). I employed this approach by selecting several "focused codes" from which I created poems using participants' words only (see Leavy, 2009, pp. 75-81 for an example of this process and resulting poem). While the benefits of this approach included focusing on participant perspectives and distilling the data down to main points which could be easily communicated to broad audiences, there were many limitations as well. For example, by relying only on verbatim transcript the creative and aesthetic possibilities were greatly limited. Also, my goal of teaching what I had personally learned from the research experience was still unfulfilled. It was at that point that I returned to the data for a third and final time. 


\section{Tri-Voiced Poems}

During my final immersion in the data I created poems that merge the transcript data, my own voice, and the literature review (which is informed by a feminist social constructionist perspective). This method is closely tied to "interpretive poetry" in Langer and Furman's terms; however, I term this method tri-voiced poems to denote the explicit merging of participant, researcher, and literature voices (Leavy, 2009b). This kind of poetic interpretation and representation merges my understanding of the data as a whole with voices from the literature review and thus fulfilled my desire to share my perspective and "teach what I had learned." This method of "tri-voiced poems" links the participants' words, the literature and my perspective. Prendergast (2009) conducted a meta-analysis of poetic forms of inquiry and determined that three voices emerge in the different forms: the researcher, participants' and literature. Therefore, it seems natural to create an approach that is attentive to all three voices. In this regard Faulkner (2009) suggests that researchers can create their own poetic forms as they explore research-driven poetry. Two sample tri-voiced poems follow, the first derived from the interviews with the heterosexual participants and the second based on data from the lesbian and bisexual participants (for the complete set of poetic works, see Leavy, 2009b).

\section{Girl-Box}

I never felt pretty

looking in the mirror

all I could see

is what I longed to be

girls are supposed to be pretty

beauty bouncing off screens

and onto all their eyes

a laser onto me

the boys should look at me

so I focus on what I wear

but they don't see me

and I feel the girls stare 
we are in competition

to be the thinnest

the best package

so I put my game-face on

I paint my face

with protection

and try to blend

into their projection

\section{Bi-Locate}

In her eyes

I finally saw

someone seeing me

and I tried to see myself

Where do I begin?

Where do they end?

I never quite fit

the girl-box

so I discovered

how to walk in it

carve my way through it

and build a third space

with Pride

I learned to bi-locate

in their world

and hers 


\section{Conclusions}

This article has developed out of a project that investigates female body image within the context of sexual identity. The original interview data suggested that three factors converge to contribute to overall body satisfaction and dissatisfaction: 1) the internalization/rejection of dominant femininity, 2) the availability of validated alternate femininities (that do not preclude dating/partnering), and 3) one's place within a subculture as a mediator of dominant beauty norms and values.

Overwhelmingly, the heterosexual participants accepted the dominant construction of femininity and its prescribed beauty ideal as the only legitimized enactment of femininity. Accordingly, the participants idealized thinness, feared musculature, but desired large breasts (all congruent with patriarchal constructions of femininity). Most notably the participants viewed adherence to dominant femininity as necessary for procuring dating opportunities and correspondingly viewed "getting boys" (a phrase uttered in many interviews) as a necessary precondition for happiness or ultimate happiness itself.

The lesbian and bisexual participants differed greatly from the heterosexual women, noting high levels of body acceptance. Overall, several interrelated points emerge from their interviews. First, these women live both inside and outside of the dominant culture. As such, they understand the dominant construction of femininity; however, their internalization of it is mediated by both their feelings of exclusion from it and by the availability of viable alternate "lesbian" femininities, that do not preclude (and may foster) dating opportunities. Second, due to their immersion in both dominant culture and a subculture, these participants developed a "double consciousness" (Du Bois, 1903) in which they negotiated the appearance values of two cultural groups, with competing and contradictory body norms. Third, inclusion in specific subculture groups at the community level, such as PRIDE, served as a mediator of dominant femininity and provided a supportive environment in which women came to develop self-acceptance.

The question undertaken in this article is how to best represent this data. What I have learned is that the best form for data representation is intimately linked to one's goals. In this project I had multiple goals that developed over time and thus I needed multiple forms of representation. With respect to my goals of sharing the research findings with diverse women (including college-age women), using the data as a vehicle for conversation with women and ideally education, and sharing what I 
learned from the research project, I found the tri-voiced method of poetic representation very useful.

I have presented several of the tri-voiced poems that emerged from this project at an international women's studies conference. The poems opened up the most robust conversation I have ever been a part of at a conference. In fact, the postpresentation discussion period was dominated by discussions surrounding these poetic works. International researchers and students from vastly different settings were able to relate to the poems. Session participants spoke about how much they could relate to the poems, how the poems reminded them of issues they discuss in their classes, and in one instance how they could use a similar poetic form in their research in order to reach public audiences. Additionally, I have used the poetic works in sociology courses I have taught as a means of beginning conversations about body image and media. Students have responded very strongly to the poems and they have stimulated great intellectual exchange in the classroom. In these ways, the poems facilitated my goals of opening up conversation, promoting critical thinking and educating. Given the subject of the study, I also think the artistic form helped mediate possible stereotyped thinking, if not directly challenging that kind of thinking. In this regard the poetic works can help build empathy and create understanding across differences - $a$ theme which emerged in my classroom conversations about the poems. Of course there are limitations to this approach as well.

First, readers have no way of knowing how much of the emphasis in the trivoiced poems is grounded in the researcher's perspective, the literature or the interview data. The process of their creation is invisible. In this instance, my voice dominates the poetic works. I emphasized my perspective (because participant and literature perspectives had been emphasized in earlier works). However, my perspective was intimately shaped by the interview data and my immersion in the related literature and I feel the resulting poetic works are "true" to the participants' stories. With this said, the process remains invisible to readers or audience members. Researchers working with this poetic form may consider giving drafts of their poems to their research participants for feedback. This may add a dimension of authenticity to the resulting work.

Second, I am not a skilled poet, nor are many researchers or students who may wish to engage with poetic analysis and representation. While some researchers suggest that poems used in social research must meet aesthetic and artistic criteria developed in the arts (for example, see Faulkner, 2009), I disagree. While ideally research-driven poetic works are attentive to the craft of poetry, they need not be 
"great" poems per se in order to be useful. Again, the question is:"What is your goal?" In this project my goal was to share what I had learned, reach diverse audiences of women and promote dialogue, understanding and education. The poems facilitated these objectives. While the poetic works are not great works of art, they are effective tools. I suggest when evaluating research poetry that researchers shy away from questions like:"Is it a good poem?" and rather ask:"What is this poem good for?"

\section{Notes}

1. Stonehill College students Lisa Hastings and Alyssa Voss contributed to the research about body image and sexual identity. Thank you to Stonehill student Meaghan Stiman for her assistance with the references and formatting. The original interview research was supported, in part, by a FSS grant from The Society for the Study of Sexuality. An earlier version of this paper was presented at the Women's Worlds Congress, Madrid, Spain, July 5, 2008 in a session organized by Dr. Judith Lorber.

2. The full research report (Leavy \& Hastings, 2010) can be retrieved at http:// www.ejhs.org/volume13/bodyimage.htm.

\section{References}

Berg, B. L. (2001). Qualitative research methods for the social sciences ( $4^{\text {th }}$ ed.). Boston: Allyn \& Bacon.

Brady, I. (2004). In defense of the sensual: Meaning construction in ethnography and poetics. Qualitative Inquiry, 10(4), 622-644.

Calafell, B. M. (2004). Disrupting the dichotomy: 'Yo soy Chicana/o?' in the new Denzin, N.K. (1997). Interpretive ethnography: Ethnographic practices for the $21^{\text {st }}$ century. Thousand Oaks, CA: Sage Publications.

Du Bois, W. E. B. (1903). The Souls of Black Folk. Chicago: A.C. McClurg \& Co.
Eisner, E. (2002). The arts and the creation of mind. New Haven, CT:Yale University Press.

Ellis, C., \& Bochner, A. P. (2000). Autoethnography, personal narrative, reflexivity. In N. K. Denzin \& Y. S. Lincoln (Eds.), Handbook of qualitative research (2nd ed., pp. 733-768). Thousand Oaks, CA: Sage Publications.

Ely, M., Viz, R., Downing, M., \& Anzul, M. (1999). On writing qualitative research: Living by words. London: Falmer Press.

Faulkner, S. L. (2005, May). How do you know a good poem? Poetic representation and the case for criteria. Symposium conducted at the $1^{\text {st }}$ international 
conference of qualitative inquiry, UrbanaChampaign, Illinois.

Faulkner, S. L. (2009). Poetry as method: Reporting research through verse.CA: Left Coast Press.

Glesne, C. (1997). That rare feeling: Re-presenting research through poetic transcription. Qualitative Inquiry, 3, 202-222.

Hartnett, S. J. (2003). Incarceration nation: Investigative prison poems of hope and terror. Walnut Creek, CA: AltaMira Press.

Hesse-Biber, S., \& Leavy, P. (Eds.). (2006). Emergent methods in social research. Thousand Oaks, CA.: Sage Publications.

Hesse-Biber, S., \& Leavy, P. (Eds.). (2008). Handbook of emergent methods. New York: Guilford Publications.

Kristeva, J. (1984). Revolution in poetic language. M. Weller (Trans). New York: Columbia University Press. (Original work published 1974).

Langer, C., \& Furman, R. (2004). The tanka as a qualitative research tool: A study of a Native American woman. Journal of Poetry Therapy, 17(3), 165-171.

Leavy, P. (2009). Method meets art: Arts-based research practice. New York: Guilford.

Leavy, P. (2009b). Fractured Femininities /Massacred Masculinities: A Poetic Installation, Qualitative Inquiry, Nov 2009; vol. 15: pp. 1439-1447.
Leavy, P., \& Hastings, L. (2010). "Body Image and Sexual Identity: An Interview Study with Lesbian, Bisexual and Heterosexual College Age Women." Electronic Journal of Human Sexuality. Vol. 13. May 3, 2010.

Madison, D. S. (2005). Critical ethnography: Method, ethics, and performance. Thousand Oaks, CA: Sage.

Pelias, R. (2004). A methodology of the heart: Evoking academic and daily life. Walnut Creek, CA: AltaMira Press.

Prendergast, M. (2009). "Poem is what?: Poetic inquiry in qualitative social science research" in M. Prendergast, C. Leggo, \& P. Sameshima (Eds.). Poetic inquiry: Vibrant voices in the social sciences. Rotterdam: Sense Publishers.

Richardson, L. (1998). Skirting a pleated text:Dedisciplining an academic life. Qualitative Inquiry, 3, 295-304.

Richardson, M. (1998). Poetics in the field and on the page. Qualitative Inquiry, 4, 451-462.

Weiss, R. S. (1994). Learning from strangers: The art and method of qualitative interview studies. New York: The Free Press. 


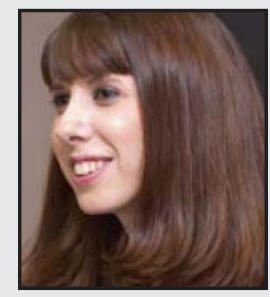

Patricia Leavy is Associate Professor of Sociology and Founding Director of Gender Studies (2004-2008) at Stonehill College in Easton, MA. She is the author of Iconic Events:Media, Politics and Power in Retelling History (Lexington, 2007), Method Meets Art: Arts-Based Research Practice (Guilford, 2009) as well as co-author of Feminist Research Practice: A Primer (Sage, 2007) and The Practice of Qualitative Research, $2^{\text {nd }}$ Edition (Sage, 2011). She is co-editor of several books, including Handbook of Emergent Methods (Guilford, 2008). She is the editor for the Oxford University Press book series Understanding Qualitative Research.

LINK TO:

http://www.stonehill.edu/x9211.xml 